\title{
$3 \operatorname{sic} 2 \operatorname{tar} 83$ \\ DXE/PR/88440-T/S
}

\section{FUNDAMENTAL STUDIES IN PRODUCTION OF $\mathrm{C}_{2}-\mathrm{C}_{4}$ HYDROCARBONS FROM COAL}

Progress Report No. 1

(covering the period September 1 - November 30, 1988)

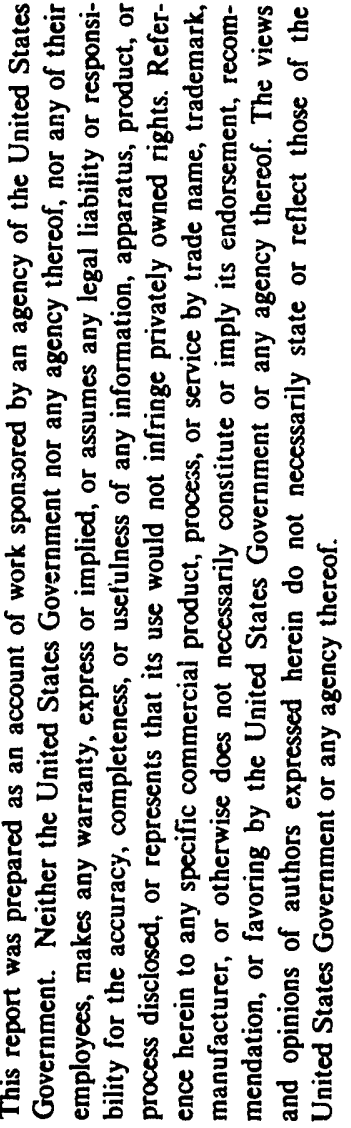

\author{
Wendell H. Wiser and Alex G. Oblad \\ Principal Investigators \\ Department of Fuels Engineering \\ University of Utah \\ Salt Lake City, Utah 84112
}

Prepared for the United States Department of Energy
under Grant No. DE-FG22-88PC88940

December, 1988 


\section{PERSONNEL}

In addition to the Principal Investigators, research personnel participating in this project during the reporting period are:

Dr. K.S. Yang, Postdoctoral Fellow

Mrs. Kui Liu, Graduate Student

\section{OBJECTIVES AND SCOPE OF THE RESEARCH PROJECT}

An envelope of parameter values has been experimentally identified in our laboratory, heretofore unexplored, for the catalytic hydrogenation and hydrocracking of coal which leads to yields of $\mathrm{C}_{2}-\mathrm{C}_{4}$ hydrocarbons in excess of 50 weight percent of the coal, in a direct, single stage process under mild conditions. In this research program, an innovative and highly sophisticated reactor system, designed and constructed by us, will obtain data to define the reaction pathways leading directly from coal to high yields of $\mathrm{C}_{2}-\mathrm{C}_{4}$ hydrocarbons, and to provide insight into the mechanisms of the conversion reactions. A computer program will be developed to define the maximum yields of $C_{2}$, $\mathrm{C}_{3}$, and $\mathrm{C}_{4}$ hydrocarbons thermodynamically possible in such a system, as a function of temperature, pressure, and percent steam in the steam-hydrogen stream to the reactor, for the type of dual-functional catalyst identified as essential to the conversion process. The process will then be optimized for production of each of the hydrocarbons $\mathrm{C}_{2}, \mathrm{C}_{3}$, and $\mathrm{C}_{4}$, and for production of olefins among these hydrocarbons. 


\section{ACTIVITY FOR THE REPORTING PERIOD}

The intent in this research program, as indicated in the budget of the proposal, is to provide for two graduate students, one assigned to Task $A$ and the other to Task B. The timing of the award creates a slight problem. Good graduating students who intend to pursue graduate study make their commitments to institutions and graduate programs by March. When we were advised in May, 1988, that we were to be funded, good graduate students were difficult to recruit. However, I have been successful in recruiting one good student who is assigned to Task B (Mrs. Kui Liu). I have employed a very good Postdoctoral Fellow (Dr. K.S. Yang), assigned to Task A on a part-time basis for the design and construction of the special reactor system. When a second strong graduate student can be found, such student will replace Dr. Yang. This arrangement permits us to pursue the objectives of the research program without delay.

\section{TASK A}

Dr. Yang has previously conducted research, as well as attending graduate classes, concerned with the chemical structure of coal, the chemistry of coal conversion to liquids and gases, and application and function of catalysts in the conversion processes. Dr. Yang was thus able to commence immediately with the design of the special reactor system. 
A block diagram of a preliminary design for the special reactor system is presented in the accompanying figure. The reactor is designed to accommodate pressures to 3,000 psia at temperatures to $550^{\circ} \mathrm{C}$. In the interest of economy, the reactor proper is of small diameter, $3 / 8$ inch inside diameter. Coal is fed as a slurry in an appropriate solvent, with the catalyst as a fine powder mixed with this slurry. Under steady-state operation, the solvent will be a selected, process-derived liquid. Under optimum operating conditions, the liquid removed as a product will be limited to the amount required to slurry the feed coal, with no net liquid product. A solids stream is also removed from the low pressure side, consisting of the inorganic material from the coal, any unreacted portions of the organic material of the coal, and spent catalyst for regeneration or disposal.

The principal intended product from the reactor, namely $\mathrm{C}_{2}-\mathrm{C}_{4}$ hydrocarbons, is removed from the gas stream exiting the top of the low-pressure side. The exact nature of this gas separator has not as yet been determined. Hydrogen in this recycle gas stream will not be removed, but will be fed, along with fresh hydrogen, to the high pressure reactor. By appropriate adjustrnent of the various streams, it is possible to operate the reactor over the full range from a single pass to total recycle (analogous to total reflux). It is also possible to adjust the residence time per pass to desired values over a wide range of values. 
Liquid samples for analysis are taken in the area of the liquid product port, and gas samples from the recycle-gas line. These sampling ports are not yet located on the diagram.

Since the reactant stream passing through the reactor contains solids (coal, catalyst, inorganic residue), provision $m$ sst be made for continuous agitation in the reactor, to keep these solids continually suspended and to avoid plugging. Since the reactor diameter is small, this agitation is provided by the gas stream entering the bottom of the high pressure reactor. A velocity balance is maintained between the gas stream entering the bottom of the reactor and the liquids and solids entering the top, such that a gas stream exits the top of the reactor while a stream of solids and liquids exits the bottom. Both of these streams proceed to the low pressure side, which operates at reduced temperature $\left(<50^{\circ} \mathrm{C}\right)$ and reduced pressure. Here most of the products heavier than about $C_{5}$ will be condensed, as determined by the vapor pressures.

The reactor configuration, as depicted in the accompanying diagram, is believed to be technically operable in the gross sense. It is still undergoing refinement prior to actual construction. Orders are now being placed for certain components. Calculations are in progress to determine the range of capacities desired for such components as the slurry pumps and compressor. 


\section{TASK B}

Mrs. Liu, the graduate student, possesses a B.S. degree in Chemical Engineering, but has not previously studied the chemistry of coal and/or coal conversion. Her time during this first quarter has been devoted to reading selected materials concerned with the chemical structure of coal, the chemistry of conversion of coal to liquids and gases, and the application of catalysts to the conversion processes. She is now beginning consideration and application of these principles in relation to specific tasks. 


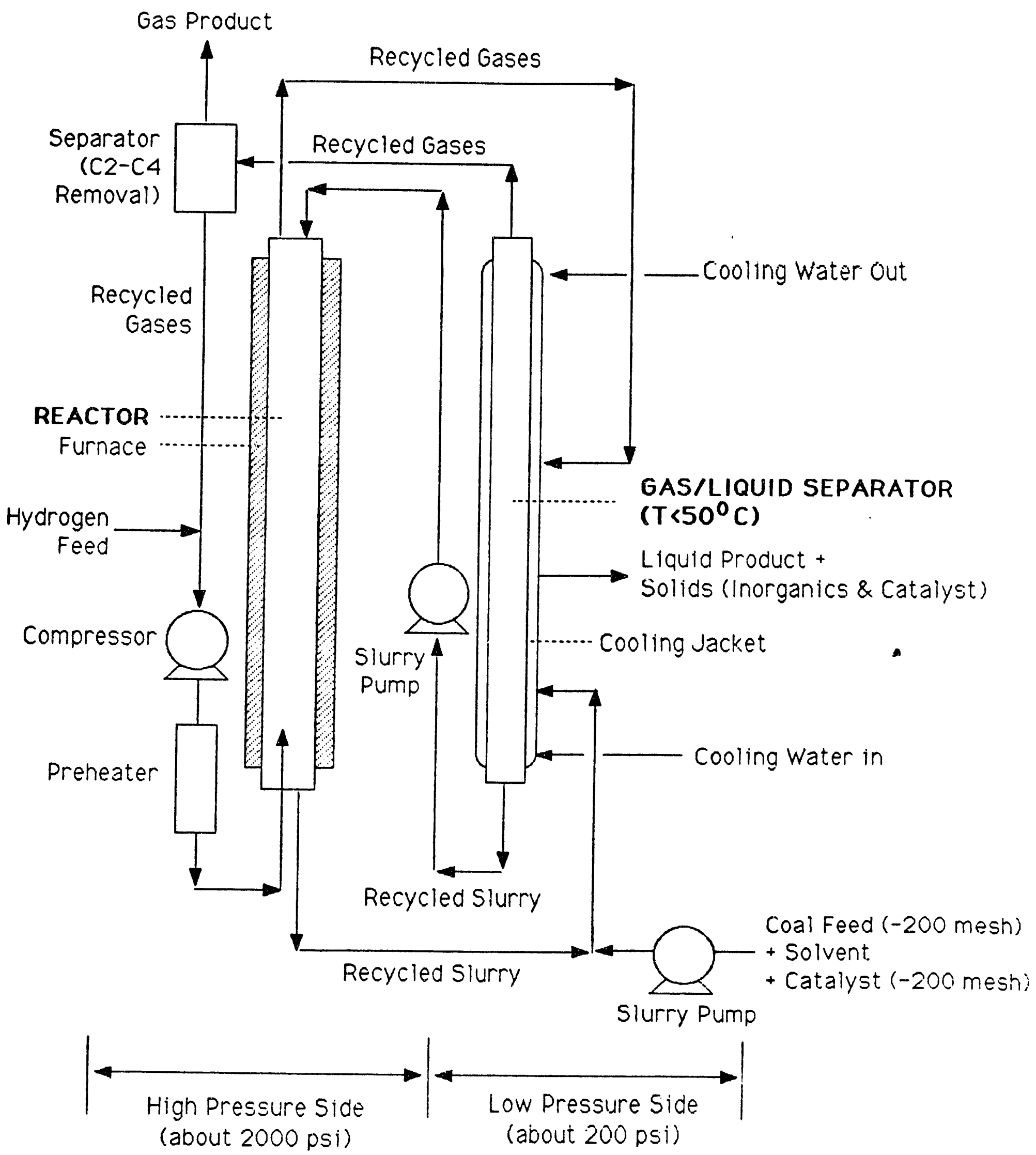




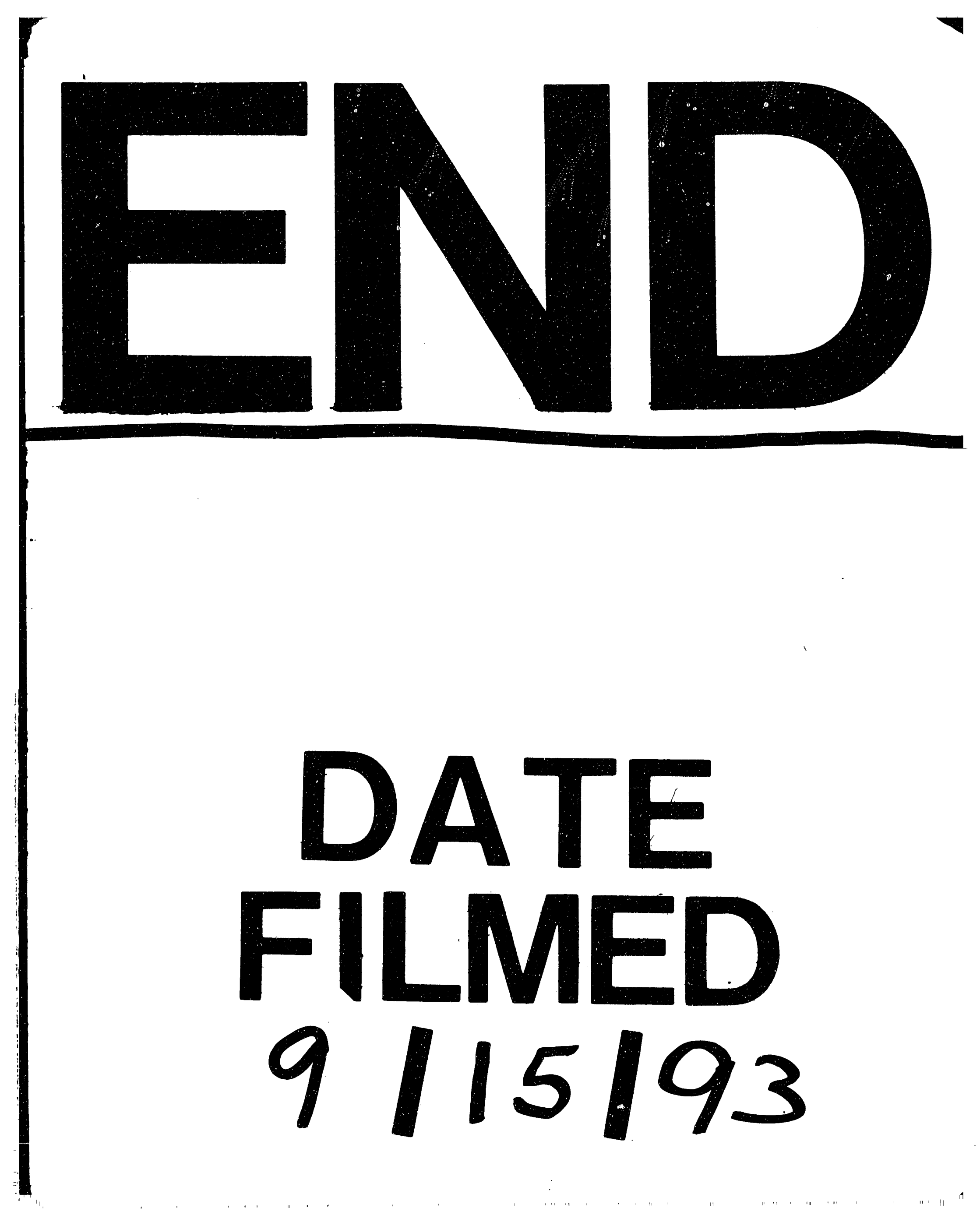


